\title{
Philosophy of language and mind
}

\author{
Peter Pagin · Robert van Rooij • Jonas Akerman
}

Received: 20 February 2013 / Accepted: 20 February 2013 / Published online: 6 March 2013

(C) Springer Science+Business Media Dordrecht 2013

This special issue contains a number of papers selected on the basis of presentations of the first Philosophy of Language and Mind (PLM) conference, organized by the PLM network. The PLM network was established in 2010, with the purpose of furthering the philosophy of language and the philosophy of mind in Europe. The original members were the Department of Philosophy at CEU, Budapest; Arché at the University of St Andrews; LOGOS at the University of Barcelona (mainly); CLLAM at the Department of Philosophy, Stockholm University; CSMN at the University of Oslo; Institut JeanNicod, Paris; ILLC at the University of Amsterdam; IP at University of London, and NIP at the University of Aberdeen. In 2011 PLM was joined by ILCLI at the University of the Basque Country, San Sebastian, and by the Institute of Philosophy II at the Ruhr University Bochum.

For furthering its goals PLM organizes a philosophy of language and mind conference every second year, an internal workshop every second year, and every year a masterclass. PLM also endorses the Amsterdam Graduate Conference. The first internal workshop took place in Dubrovnik in September 2012, and the first masterclass, with Dan Sperber, at Jean Nicod in Paris, in December 2012. The second PLM Conference will take place in Budapest in September 2013.

The first PLM Conference took place in Stockholm in September 2011, organized by CLLAM. Five key-note talks and 20 contributed talks were given. The contributed

P. Pagin $(\varangle) \cdot$ J. Akerman

Department of Philosophy, Stockholm University, Stockholm, Sweden

e-mail: peter.pagin@philosophy.su.se

\section{J. Akerman}

e-mail: jonas.akerman@philosophy.su.se

R. van Rooij

Department of Philosophy, University of Amsterdam, Amsterdam, The Netherlands

e-mail: r.a.m.vanrooij@uva.nl 
papers were selected among 108 submissions after a call for papers. Among the 25 papers presented, six were selected to be included in a special issue of Synthèse. Two of these, by Elisabeth Pacherie and Francois Recanati, were invited, and four, by Craig French, Peter Fritz, Marie Guillot, Nat Hansen, were contributed. The variety of topics among these papers reflects the width of the PLM area; from model-theoretic and formal semantics (Fritz), over methodological reflections on experimental philosophy of language (Hansen) and the semantics for perception reports (French) to the philosophy of mind in papers about mental files (Recanati), de se thoughts (Guillot), and shared intentions (Pacherie). Below we will give a brief introduction of the papers of this special issue.

Given that states of seeing that $\mathrm{p}$ appear to be both perceptual and propositional, one may wonder how one could even make sense of the idea of accounting for such states in terms of a non-propositional view of perceptual experience. In his contribution to this volume, Craig French takes on this challenge on behalf of defenders of nonpropositional views. He proceeds by offering a semantics for 'see' (in its relevant sense) according to which an ascription of a state of seeing that $p$ ascribes knowledge that $p$ on the basis of visual perception. Such states are propositional in virtue of knowledge being a propositional attitude, and perceptual in virtue of being individuated in terms of visual perception. Yet, they need not be taken to constitutively involve a perceptual propositional attitude, and thus the resulting view of seeing that $\mathrm{p}$ is compatible with a non-propositional view of perceptual experience.

Two-dimensional semantics is a theory in the philosophy of language that provides an account of meaning which is sensitive to the distinction between context of utterance and context of evaluation. By doing so it is able to make a distinction between necessity and a priority in terms of so-called 'primary' and 'secondary' intensions. But how are such intensions composed, and how do they interact? Two-dimensional semantics has been criticized for being unable to give a satisfactory answer to these questions. The main aim of Peter Fritz's contribution to define a semantics for a propositional modal logic with separate epistemic and 'metaphysical' modalities to answer these worries. He shows how primary and secondary intensions can be composed and how they can interact with each other. Peter Fritz describes some interesting philosophical properties of this semantics, and discusses how his way of accounting for the interaction of the different modalities can solve the so-called nesting problem.

As Nat Hansen observes, the so-called context shifting experiments that have been invoked in order to elicit such intuitions have often been conducted informally "from the armchair". But with the rise of the experimental philosophy movement, recent years have seen a trend towards conducting context shifting experiments formally, which involves collecting large numbers of judgments about the use of linguistic expressions and subjecting those judgments to statistical analysis. Hansen provides an insightful discussion of the relation between these different methods, and suggests how informal experiments can be improved by taking into account some lessons learned in the development of formal experiments. In particular, he suggests how they can be redesigned in order to avoid distortions due to experimenter bias and certain restrictions on response options.

Semantic relativism grew out of attempts to account for 'faultless disagreement' in dialogues involving, for instance, expressions of taste. According to semantic rela- 
tivism, truth might depend on features absent in the context that help to determine what is said. Using this framework to represent $d e$ se attributions, what results is an analysis of de se thoughts that dispenses with self-representation. Marie Guillot's paper is a critical discussion of this strategy. She points out that such an analysis cannot fully account for the epistemic profile that sets de se thinking apart. The problem is that the primitive notion of 'centre' used in semantic relativism is required to be rather thin to account for the semantic facts, but needs to be much richer to account for the peculiarities of de se thoughts.

Elisabeth Pacherie's paper is concerned with a puzzle about joint agency. In joint agency participants attempt to jointly achieve a shared goal. The crux here is to spell out what is involved in doing something jointly. Several attempts have been made to spell this out in terms of *shared intentions*. Received accounts of shared intentions, however, appeal to thoughts about the thoughts of other agents in ways that require advanced mentalizing abilities. This is problematic, since empirical studies credit children with joint action before they acquire the mentalizing abilities required. The solution is to either forgo the appeal to shared intentions, or to develop a less demanding conception. Pacherie chooses the latter, and spells out a proposal for shared intentions "lite". She makes use of the idea of *team agency* from game theory, and the associated psychological idea of self framing in which an agent conceives of herself as a group member.

Francois Recanati presents the basic features of the *indexical model* of mental files, and defends it against several interrelated objections. According to this model, mental files refer to objects in a way that is analogous to that of indexicals in language: a file refers to an object in virtue of a contextual relation between them. For instance, perception and attention provide the basis for demonstrative files. Several objections, some of them from David Papineau, concern the possibility of files to preserve and add information about objects across contexts. How is it possible to think about the same object when the subject is no longer in the original context? How is it possible to think of a perceived object as already known? Can this be done without an explicit identity judgment? Recanati answers these questions by invoking mental files of non-basic kinds and by describing the cognitive dynamics in which they take part. 